\title{
Ontogeny of swimming behaviour of two temperate clingfishes, Lepadogaster lepadogaster and L. purpurea (Gobiesocidae)
}

\author{
Ana M. Faria ${ }^{1,2}$, Emanuel J. Gonçalves ${ }^{1, *}$ \\ ${ }^{1}$ Eco-Ethology Research Unit, Instituto Superior de Psicologia Aplicada, R. Jardim do Tabaco 34, 1149-041 Lisboa, Portugal \\ ${ }^{2}$ Centre of Marine Sciences, CCMAR, University of Algarve, Campus de Gambelas, 8005-139 Faro, Portugal
}

\begin{abstract}
Gobiesocids are typically reef-dwelling species whose larvae have been found in several nearshore rocky environments; this suggests a possible retention pattern for these species. Retention may occur due to the physical features of an area and/or active larval behaviour, such as swimming abilities. In the laboratory, we measured the ontogeny of swimming behaviour (routine speed and critical speed, $U_{\text {crit }}$ ) of 2 clingfish species, Lepadogaster lepadogaster and L. purpurea. $L$. lepadogaster larvae swam better than $L$. purpurea larvae, but this difference might be related to differences in water temperature, since the former is a spring spawner, whereas the latter spawns during winter. It is well known that water viscosity increases with decreasing temperature, making swimming more difficult. Routine and critical swimming speeds of larvae of both species increased with ontogeny (size) despite high variability at any ontogenetic state. $U_{\text {crit }}$ ranged from 1 to 9.4 and 1.2 to $6.5 \mathrm{~cm} \mathrm{~s}^{-1}$ in L. lepadogaster and L. purpurea, respectively. Routine speeds were $\sim 18$ to $19 \%$ of the maximum $U_{\text {crit }}$ registered for both species. Interestingly, swimming speed started to decrease as settlement size (10 to $11 \mathrm{~mm}$ total length) was approached, concurrent with the development of a ventral sucking disk that allows individuals to attach to the bottom of the swimming chamber and counteract strong currents. This shift in swimming behaviour that is associated with settlement is probably an adaptation to the cryptobenthic mode of life of these fish.
\end{abstract}

KEY WORDS: Gobiesocidae $\cdot$ Swimming performance $\cdot$ Ontogeny $\cdot$ Retention $\cdot$ Behaviour

\section{INTRODUCTION}

Fish inhabiting nearshore reefs are valuable elements of coastal biodiversity, playing an important ecological role in the functioning of littoral ecosystems (Depczynski \& Bellwood 2003, La Mesa et al. 2004). Current gaps in knowledge on recruitment of marine species justify an increased effort to understand rocky coastal fish assemblages. Cryptobenthic fish are smallbodied fish $(5$ to $10 \mathrm{~cm}$ ) that exploit complex habitats, typically placing a physical barrier between small fish and sympatric predators' (cf. Miller 1979). The early stages of these fishes, in particular, are still largely unknown, but some biological characteristics, e.g. a short pelagic larval duration (PLD) and large larval sizes at hatching, suggest that some species may be able to remain nearshore. Several studies of tropical and temperate reef fishes have found that larvae hatching from demersal eggs are more abundant nearshore, whereas those that are generally derived from pelagic eggs are more widely distributed (e.g. Leis \& Miller 1976, Marliave 1986, Leis \& Goldman 1987, Suthers \& Frank 1991). Pelagic eggs are typically smaller than demersal eggs, and usually produce smaller larvae (Thresher 1984) with less-developed sensory systems and swimming abilities (Blaxter 1986, Miller et al. 1988, Fuiman 2002, Snelgrove et al. 2008). PLD has also been proposed as one of the primary cor- 
relates of dispersal ability (Thresher et al. 1989, Sponaugle et al. 2002, Lester \& Ruttenberg 2005) in that species with short PLD having potentially more limited dispersal (Swearer et al. 2002) than species with longer PLD (Bradbury et al. 2008).

Clingfish species (family Gobiesocidae) occur worldwide, in many different habitats in tropical and temperate seas (Briggs 1955, 1986). Although clingfish larvae have been collected in several studies in nearshore rocky environments (Marliave 1986, Kingsford \& Choat 1989, Brogan 1994, Tilney et al. 1996, Sabatés et al. 2003, Beldade et al. 2006a, Borges et al. 2007), knowledge of their larval behaviour and ecology is extremely poor. At the Arrábida Marine Park (Portugal), R. Borges \& E. J. Gonçalves (unpubl. data) caught large numbers of gobiesocid larvae of all size classes with light traps placed over the nearshore rocky reefs. In contrast, no larvae of these species (Borges et al. 2007) were collected in offshore sampling. These findings suggest nearshore retention of these fishes. As clingfish larvae begin to switch from a pelagic to a benthic environment, they develop a ventral adhesive disk, which is an adaptation to their cryptobenthic mode of life. Once larvae settle on a hard substrate, the individuals remain hidden underneath rocks during their entire adult life (Gonçalves et al. 1998).

Retention of larvae near reefs is increasingly recognized as a central mechanism of self-recruitment for some coral-reef populations (e.g. Jones et al. 1999, Swearer et al. 2002, Taylor \& Hellberg 2003). One of the advantages of nearshore retention for coastal species is the enhanced ability to locate a suitable habitat at settlement. Dispersal may increase mortality because variable oceanographic processes influence larval transport, both temporally and spatially, and if larvae are not transported to an appropriate habitat, they can be lost (Hickford \& Schiel 2003). Retention and/or dispersal may depend on particular physical features of an area and/or active larval behaviour, such as swimming abilities. Recent in situ and laboratory studies have shown strong swimming capabilities in coral-reef fish larvae (e.g. Leis \& Stobutzki 1999, Fisher \& Bellwood 2002, 2003, Fisher 2005, Leis et al. 2009a, b), which are sufficient to influence oceanic dispersal and return to adult habitats (e.g. Leis \& Carson-Ewart 1997, Stobutzki \& Bellwood 1997). Besides a strong swimming ability, larvae also need to detect suitable habitats at settlement, because successful settlement is unlikely solely achieved by chance (Jones et al. 1999, Cowen et al. 2002).

Studies on the swimming performance of temperate fish larvae are few (e.g. Dudley et al. 2000, Clark et al. 2005, Leis et al. 2006a, Guan et al. 2008, Faria et al. 2009) relative to those in tropical reef environments (e.g. Stobutzki \& Bellwood 1994, 1997, Fisher et al.
2000, 2005, Fisher 2005, Leis et al. 2007, 2009a,b). Moreover, most investigations have concentrated on late-stage larvae, and rarely consider the ontogeny of swimming behaviour (but see Clark et al. 2005, Guan et al. 2008, Leis et al. 2007, 2009a,b, Faria et al. 2009). Two of the most common measurements of swimming capability are routine speed and critical speed ( $\left.U_{\text {crit }}\right)$. Routine swimming is generally considered to be important in foraging and provides critical information on the ability of larvae to influence their dispersal patterns, because it is an estimate of the undisturbed, dayto-day speeds of larvae (Fisher \& Leis 2009). $U_{\text {crit }}$ is a useful estimate of maximum swimming performance of fish larvae (Plaut 2001, Fisher 2005). Although $U_{\text {crit }}$ is a measure of prolonged swimming speed that is rarely, if ever, experienced by fish in nature (Plaut 2001), it provides a useful metric for comparing taxa or developmental stages (Leis 2006), and can be correlated with other more ecologically relevant measures of swimming ability, such as routine, in situ and endurance performance.

In this study, we characterize the ontogeny of $U_{\text {crit }}$ and routine swimming speed of 2 temperate Gobiesocidae species, Lepadogaster lepadogaster and L. purpurea. These closely related species are quite similar in morphology, but differ in their breeding seasons (Henriques et al. 2002).

\section{MATERIALS AND METHODS}

Larvae. Larvae were obtained from breeding individuals that were maintained in separate $250 \mathrm{l}$ aquaria. Females laid eggs on the underside of rocks that were placed in the aquaria, and eggs were guarded by the male. As hatching approached, rocks with eggs were removed from the parental aquaria and transferred to a 30 l larval rearing tank where larvae hatched. Aquaria were maintained at 14.5 to $15.5^{\circ} \mathrm{C}$ for Lepadogaster purpurea and 16 to $17^{\circ} \mathrm{C}$ for L. lepadogaster, which was consistent with the mean water temperature at the sampling area during the testing dates (Henriques et al. 2002). All tanks were maintained at a constant salinity of 34 . Larvae were fed $3 \times \mathrm{d}^{-1}$ with Brachionus sp. that was enriched with Selco (Artemia systems), which was gradually replaced with Artemia sp. nauplii 5 d after hatching. Data were collected throughout ontogeny using $>1$ cohort of larvae in the same day (6 cohorts for L. lepadogaster and 5 cohorts for L. purpurea).

Critical swimming speed. $U_{\text {crit }}$ was measured using a swimming chamber, following the protocols of Stobutzki \& Bellwood (1994, 1997). The chamber was made of clear Perspex with 6 parallel swimming lanes (each $30 \times 50 \times 180 \mathrm{~mm}, \mathrm{~W} \times \mathrm{H} \times \mathrm{L}$ ). A removable lid 
allowed introduction and removal of fish from the lanes. A strip of black tape on the top of the lid provided fish with a visual reference to maintain position in the flow, and mesh screens at the upstream and downstream ends of each lane retained larvae in the chamber. Flow straighteners (40 mm long) at the upstream end of each lane minimized turbulence. Previous work demonstrated that water velocity was not significantly different between the centre of the lane and $5 \mathrm{~mm}$ from the wall for typical $U_{\text {crit }}$ values (Stobutzki \& Bellwood 1997, Stobutzki 1998, Fisher et al. 2000). Experimental observations also confirmed that larvae had no depth preference in the chamber. The swimming chamber was part of a closed-flow system in which a submersible pump moved water from a collecting tank to the swimming chamber. A ball valve at the upstream end of the swimming chamber controlled water velocity. A protractor that was mounted on the valve handle calibrated flow rates in swimming lanes based on handle angle; for different angles, we recorded the time taken for the outlet water to fill a 51 container and divided this by the cross-sectional area and number of lanes. The flow speed for a specific valve angle was averaged from 3 trials to form a calibration curve that formed the basis for setting flow velocities for experimental runs.

The different breeding seasons for the 2 species necessitated that experiments be conducted at different times of the year: Lepadogaster lepadogaster was tested during the spring-summer months (May to July) and L. purpurea was tested in the winter months (December to March). Larvae were tested every $2 \mathrm{~d}$ from hatching to settlement for each batch (see Table 1). We tested 5 to 6 fish during the morning of each experimental day. One hour after feeding, larvae were carefully removed from the rearing tank and individually placed in large Petri dishes to acclimatize undisturbed for $1 \mathrm{~h}$ (Fuiman \& Ottey 1993). After this period, larvae were transferred to the swimming chamber (1 larva lane $\mathrm{e}^{-1}$ ), and maintained for $5 \mathrm{~min}$ at a flow speed of $1 \mathrm{~cm} \mathrm{~s}^{-1}$. The few individuals that displayed symptoms of stress (e.g. lying on the bottom or clinging to the sides) after this acclimation period were removed and replaced. Chamber water temperatures varied from 14.9 to $15.4^{\circ} \mathrm{C}(15.1 \pm 0.15)$ for $L$. purpurea experiments, and from 16.4 to $17.5^{\circ} \mathrm{C}(16.9 \pm 0.34)$ for L. lepadogaster experiments.

To measure $U_{\text {crit, }}$ we increased water velocity by $\sim 1.2 \mathrm{~cm} \mathrm{~s}^{-1}$ every 2 min until the larva was unable to swim against the current for $2 \mathrm{~min}$. Calculation of $U_{\text {crit }}$ was based on the formula of Brett (1964):

$$
U_{\text {crit }}=U+\left(t / t_{\mathrm{i}} \times U_{\mathrm{i}}\right)
$$

where $U$ is the highest speed a fish was able to maintain, $U_{\mathrm{i}}$ is the velocity increment, $t$ is the time swum in the final velocity increment, and $t_{\mathrm{i}}$ is the time interval for each velocity increment (2 min). After the test, fish were immediately photographed under a dissecting microscope and returned to the rearing aquarium.

This procedure was adopted because these species spawn few large eggs at a time and larvae are resilient to manipulation and can be kept alive through ontogeny. This strategy increases the likelihood of retesting the same larvae; however, there were between 20 and 60 larvae present in the aquarium at any given time, depending on the tested batch, and the probability of resampling the same individual was low. Closer to metamorphosis, resampling was more likely because numbers were lower. Interspecific comparison of the same developmental stage is unaffected by any retesting, and different batches were used to increase the robustness of the derived trends. Therefore, we are confident that resampling did not affect the outcome and interpretation of this study.

Routine swimming speed. The routine swimming test measured the mean rate of travel for individual larvae during undisturbed activity in the absence of food. Experiments were conducted throughout the larval period, from hatching to settlement, following the method of Fuiman et al. (1999). Five larvae of similar size were removed from the rearing tank the day prior to testing. Each of the 5 larvae was then placed on a separate glass bowl (15 cm diameter, opaque black sides) with 11 of filtered seawater at the same temperature and salinity as the rearing tank. Before each experiment, white paper was placed below the bowl to increase contrast. All but $200 \mathrm{ml}$ (1 cm depth) of water was siphoned carefully from the watch bowl to reduce measurement error that might be caused by any change in the depth of the larval position. The larva was left undisturbed for 2 min, after which its behaviour was recorded for a 2 min period. Each of the 5 larvae were tested $4 \times$. Larval behaviour was measured later through frame-by-frame analysis of video recordings. Routine swimming speed was determined for each larva by measuring the total distance covered in the $120 \mathrm{~s}$ recorded. After the test, fish were immediately photographed under a dissecting microscope, and returned to the rearing aquarium.

Data analysis. We examined the relationship between swimming performance ( $U_{\text {crit }}$ and routine speed) and total length (TL) by regressing swimming speed against size (size and length are used throughout the text as synonyms). Both the dependent and independent variables were $\log _{10}$ transformed to normalize data. To determine the best predictor of performance, critical and routine swimming speeds were regressed against TL using linear, power, logarithmic and exponential models. The linear model produced the highest $\mathrm{R}^{2}$, and was therefore adopted. For each species, mul- 
tiple regressions were used to test the relationships between the 2 independent variables (age and size) and critical speed.

Analysis of covariance (ANCOVA) was used to determine whether the slopes of the regressions of swimming performance on length differed among cohorts, with $U_{\text {crit }}$ and routine speed as the dependent variables, cohort as a fixed factor, and length as the covariate. ANCOVA was also used to test whether slopes of regressions of swimming performance on length differed among species, with $U_{\text {crit }}$ and routine speed as the dependent variables, species as a fixed factor, and length as the covariate.

Throughout ontogeny, changes in body size influence swimming speed by placing larvae in different hydrodynamic regimes. The Reynolds number $(R e)$ is a measure of the ratio of viscous to inertial forces as fish swim through water; it is commonly used to characterize different hydrodynamic conditions. Re (Webb \& Weihs 1986) was calculated for critical swimming experiments to determine whether larvae were in viscous $(R e<200)$ or inertial $(R e>200)$ conditions, using the formula:

$$
R e=U \times \mathrm{TL} / V
$$

where $U$ is the critical speed, $v$ is the kinematic viscosity of sea water (viscosity of seawater at $20^{\circ} \mathrm{C}=1.03 \times$ $10^{-6} \mathrm{~m}^{2} \mathrm{~s}^{-1}$ ) and TL is total length.

The threshold of 200 is the most conventionally used number (Webb \& Weihs 1986), and although recent experiments indicate that the viscous environment could extend to values of $R e=300$, a fully inertial environment may not come into play until $R e>1000$ (e.g. Fuiman \& Batty 1997). Moreover, these thresholds are also species-specific. Because we lack information for Lepadogaster spp., we chose to use the most conventional and conservative value of $R e$.

For progressive stages of development, we measured TL to the nearest $0.01 \mathrm{~mm}$, using Image $\mathrm{J}$ software (version 1.38). Before each photograph was taken, a transparent acetate sheet that was marked with a millimetre grid was photographed and used as reference before each measurement in the image analysis software. We used STATISTICA software (StatSoft, version 6.0) for all statistical analyses.

\section{RESULTS}

Mean larval size (TL) on Day 1 (when larvae were first tested) did not differ between species (Lepadogaster purpurea mean size $=6.3 \pm 0.53 \mathrm{~mm}$ $\mathrm{SD}$, range $=5.4$ to $7.5, \mathrm{n}=20$; L. lepadogaster mean size $=6.0 \pm 0.49 \mathrm{~mm}$
$\mathrm{SD}$, range $=5.2$ to $6.9, \mathrm{n}=14 ; t$-value $=1.80, \mathrm{df}=32, \mathrm{p}=$ $0.08)$. Growth rates were also not statistically different between species ( $L$. purpurea mean growth $=0.27 \pm$ $0.58 \mathrm{~mm} \mathrm{~d}^{-1} \mathrm{SD} ;$ L. lepadogaster mean growth $=0.19 \pm$ $1.04 \mathrm{~mm} \mathrm{~d}^{-1} \mathrm{SD}$; $t$-value $=0.26, \mathrm{df}=29, \mathrm{p}=0.80$ ).

\section{Critical swimming speed}

A total of 154 Lepadogaster lepadogaster larvae and 139 L. purpurea larvae were tested for critical swimming speeds. Of these, 9 and 6 recently hatched larvae of L. lepadogaster and L. purpurea, respectively, could not swim at the slowest tested current speed, and 11 post-settlement L. lepadogaster larvae did not swim at the maximum current speed because they had developed a ventral adhesive disc and attached to the bottom of the chamber. These individuals were excluded for all subsequent analysis, and are omitted from Table 1.

$U_{\text {crit }}$ values ranged from 1 to $9.4 \mathrm{~cm} \mathrm{~s}^{-1}$, corresponding to 1.5 to 9.6 body lengths (BL) $\mathrm{s}^{-1}$ for Lepadogaster lepadogaster over a size range of 5.1 to $10.9 \mathrm{~mm} \mathrm{TL}$ (Table 1). As expected, $U_{\text {crit }}$ increased with size $\left(F_{1,132}=\right.$ 75.90, p < 0.0001) (Table 2, Fig. 1). In L. purpurea, $U_{\text {crit }}$ also increased significantly with size $\left(F_{1,131}=283.60\right.$, $\mathrm{p}<0.0001$ ) (Table 2, Fig. 1) from 1.2 to $6.5 \mathrm{~cm} \mathrm{~s}^{-1}$ (2.1 to $6.8 \mathrm{BL} \mathrm{s}^{-1}$ ) over the size range tested (5.3 to $10.9 \mathrm{~mm}$ TL) (Table 1). In all cases, there was large variation in performance among individuals at any ontogenetic stage (Fig. 1).

In both species, critical speed increased with size over the common range tested, with an increase of 0.5 to $1.6 \mathrm{~cm} \mathrm{~s}^{-1} \mathrm{~mm}^{-1}$ growth for Lepadogaster purpurea and 0.3 to $1.2 \mathrm{~cm} \mathrm{~s}^{-1} \mathrm{~mm}^{-1}$ growth for L. lepadogaster. The incremental speed increase was significantly greater for $L$. lepadogaster $\left(F_{1,9}=32.42\right.$, $\left.\mathrm{p}<0.0005\right)$. Multiple regression analyses were significant for both species (L. purpurea: $F_{2,130}=244.55, \mathrm{p}<0.0005$, adjusted $\mathrm{R}^{2}=0.79 ;$ L. lepadogaster: $F_{2,131}=56.17, \mathrm{p}<$ 0.0005 , adjusted $R^{2}=0.45$ ). Age and size were both

Table 1. Lepadogaster lepadogaster and L. purpurea. Summary of data for measurements of critical swimming and routine swimming speeds. N: number, TL: total length, dph: days post hatching, Cohorts: number of tested cohorts. Stages of reared larvae: Pre: preflexion, F: flexion, Post: postflexion

\begin{tabular}{|lccccc|}
\hline & N & TL $(\mathrm{mm})$ & Age (dph) & Stages & Cohorts \\
\hline $\begin{array}{l}\text { Critical speed }\left(\mathrm{cm} \mathrm{s}^{-1}\right) \\
\text { L. lepadogaster }\end{array}$ & 134 & $5.1-10.9$ & $0-19$ & Pre, F, Post & 6 \\
$\begin{array}{l}\text { L. purpurea } \\
\text { Routine speed }\left(\mathrm{mm} \mathrm{s}^{-1}\right)\end{array}$ & 133 & $5.3-10.9$ & $1-21$ & Pre, F, Post & 5 \\
$\begin{array}{l}\text { L. lepadogaster } \\
\text { L. purpurea }\end{array}$ & 82 & $5.1-10.9$ & $2-19$ & Pre, F, Post & 6 \\
& 42 & $6.2-10.4$ & $2-21$ & Pre, F, Post & 5 \\
\hline
\end{tabular}


Table 2. Lepadogaster lepadogaster and L. purpurea. Relationships between critical speed $\left(U_{\text {crit }}: \log _{10}\right.$ transformed) and size (total length, TL: $\log _{10}$ transformed), $U_{\text {crit }}$ and age (dph: days post hatching), routine speed $\left(\log _{10}\right.$ transformed) and size (TL: $\log _{10}$ transformed) and routine speed and age (dph). See Table 1 for number, size and age range of tested larvae. ns: not significant $(\mathrm{p}>$ 0.05). CI: confidence interval

\begin{tabular}{|c|c|c|c|c|}
\hline & Relationship & $\mathrm{R}^{2}$ & $\mathrm{p}$ & Slope $\pm 95 \%$ CI \\
\hline \multicolumn{5}{|c|}{$U_{\text {crit }}\left(\mathrm{cm} \mathrm{s}^{-1}\right)$ vs. size $(\mathrm{mm})$} \\
\hline L. lepadogaster & $y=1.582 x-0.764$ & 0.37 & $<0.001$ & $1.582 \pm 0.359$ \\
\hline L. purpurea & $y=2.049 x-1.332$ & 0.68 & $<0.001$ & $2.049 \pm 0.241$ \\
\hline \multicolumn{5}{|c|}{$U_{\text {crit }}\left(\mathrm{cm} \mathrm{s}^{-1}\right)$ vs. age $(\mathrm{dph})$} \\
\hline L. lepadogaster & $y=0.028 x+0.389$ & 0.44 & $<0.001$ & $0.028 \pm 0.005$ \\
\hline L. purpurea & $y=0.028 x+0.263$ & 0.76 & $<0.001$ & $0.028 \pm 0.003$ \\
\hline \multicolumn{5}{|c|}{ Routine $\left(\mathrm{mm} \mathrm{s}^{-1}\right)$ vs. size $(\mathrm{mm})$} \\
\hline L. lepadogaster & $y=0.804 x+0.0004$ & 0.05 & ns & $0.804(0.61-0.92)$ \\
\hline L. purpurea & $y=1.275 x-0.640$ & 0.06 & ns & $1.275 \pm 1.610$ \\
\hline \multicolumn{5}{|c|}{ Routine $\left(\mathrm{mm} \mathrm{s}^{-1}\right)$ vs. age $(\mathrm{dph})$} \\
\hline L. lepadogaster & $y=0.00005 x+0.714$ & $<0.01$ & ns & $0.00005 \pm 0.010$ \\
\hline L. purpurea & $y=0.009 x+0.412$ & 0.02 & ns & $0.009 \pm 0.019$ \\
\hline
\end{tabular}

good predictors of critical speed, although age was a better predictor (Table 3).

Some differences in performance among cohorts were apparent for both Lepadogaster lepadogaster $\left(F_{5,127}=5.00, \mathrm{p}=0.0003\right)$ and $L$. purpurea $\left(F_{4,127}=5.71\right.$, $\mathrm{p}=0.0003)$, indicating that the slopes of the cohort regressions of $U_{\text {crit }}$ on size were not homogenous; hence, the influence of size on $U_{\text {crit }}$ differed among cohorts (Fig. 2). This cohort variation might be the result of differences in size structure or performance among

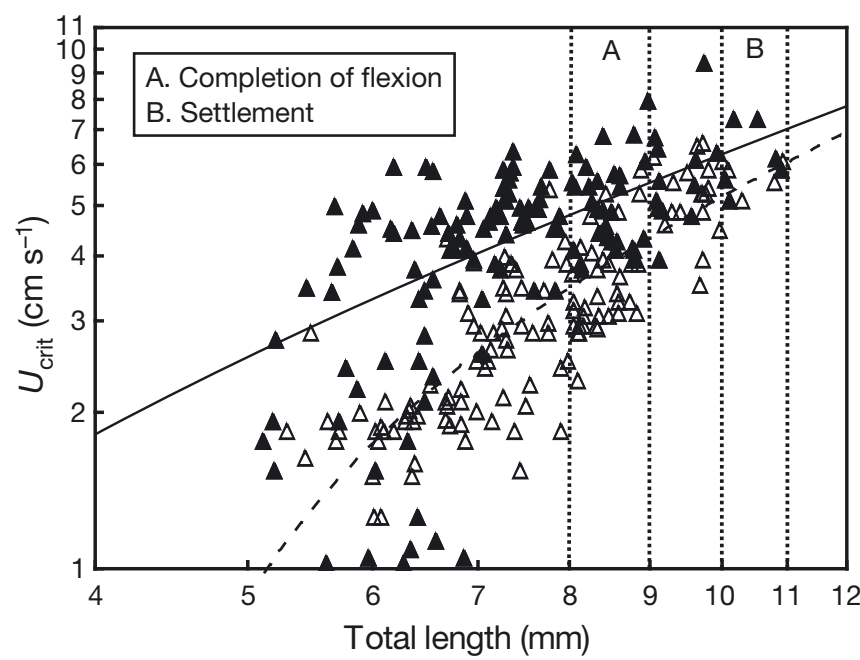

Fig. 1. Lepadogaster lepadogaster $(\mathbf{\Delta})$ and L. purpurea $(\Delta)$. Ontogenetic trends for the critical swimming speeds of larvae. Each symbol represents the test result for an individual larva. (-) Regression line for L. lepadogaster, (--) regression line for $L$. purpurea (see regression details in Table 2). Both axes are log-transformed to reflect developmental progress. (:) Size at which 2 important developmental milestones are attained: (A) completion of notochord flexion, and (B) settlement cohorts. ANCOVA comparisons between species found a significant interaction effect (species $\times$ length: $\left.F_{1,264}=111.35, \mathrm{p}<0.0001\right)$, indicating that the influence of size on $U_{\text {crit }}$ differed between species, with L. lepadogaster being a significantly better swimmer than L. purpurea (Fig. 1).

$R e$ increased as individuals developed from hatching to juveniles (Fig. 3). However, the Re of Lepadogaster purpurea was smaller than that of L. lepadogaster due to the former's slower $U_{\text {crit }}$. Before the beginning of notochord flexion (TL $<7 \mathrm{~mm}$ ), individuals of both species were clearly within a viscous hydrodynamic environment $(R e<200)$. During notochord flexion, larval swimming performance improved. After completion of flexion (8 to $9 \mathrm{~mm}$ ), individuals swam in an inertial environment.

\section{Routine swimming speed}

We tested a total of 95 larvae of Lepadogaster lepadogaster from 6 cohorts, and 49 larvae of L. purpurea from 5 cohorts for routine swimming experiments. Of these, 13 L. lepadogaster and 7 L. purpurea larvae did not swim since they were either recently hatched or settled, hence they were excluded from the analysis.

For both species, there was a nonlinear relationship between routine swimming speed and size (Lepadogaster lepadogaster: $F_{1,80}=2.85, \mathrm{p}=0.09 ;$ L. purpurea: $F_{1,40}=2.57, \mathrm{p}=0.12$ ) (Table 2, Fig. 4). Despite large variations in routine speed at any given size, swimming performance increased with development in $L$. lepadogaster, until $\sim 9 \mathrm{~mm} \mathrm{TL}$, after which it decreased (Fig. 4). Routine swimming speed varied from 0.8 to $17.8 \mathrm{~mm} \mathrm{~s}^{-1}$ (0.1 to $\left.2 \mathrm{BL} \mathrm{s}^{-1}\right)$ over a size range of 5.1 to 
Table 3. Lepadogaster lepadogaster and L. purpurea. Multiple-regression models for the relationship of critical swimming speed with 2 independent variables (age and size)

\begin{tabular}{|lcccc|}
\hline & Model F-value & Model adjusted $\mathrm{R}^{2}$ & $\mathrm{p}$-value & Beta \\
\hline L. purpurea & 244.55 & 0.79 & $<0.0005$ & \\
Age & & & $<0.0005$ & 0.59 \\
Size & & & $<0.0005$ & 0.33 \\
L. lepadogaster & 56.17 & 0.45 & $<0.0005$ & \\
Age & & & $<0.0005$ & 0.45 \\
Size & & & 0.004 & 0.27 \\
\hline
\end{tabular}

$10.9 \mathrm{~mm}$ (TL) for L. lepadogaster, and from 0.1 to $11.5 \mathrm{~mm} \mathrm{~s}^{-1}$ (0.02 to $1.6 \mathrm{BL}$ $\mathrm{s}^{-1}$ ) over a size range of 6.2 to $10.4 \mathrm{~mm}$ (TL) for L. purpurea (Tables 1 \& 2). When testing for between-cohort differences in routine swimming speed in each species, there was no significant effect of $\log _{10}$ TL (L. lepadogaster: $F_{1,75}$ $=2.62, \mathrm{p}=0.11 ;$ L. purpurea: $F_{1,36}=$ $1.53, \mathrm{p}=0.22$ ), no significant interaction (L. lepadogaster: $F_{1,75}=0.15, \mathrm{p}=$ $0.70 ;$ L. purpurea: $F_{1,36}=0.42, \mathrm{p}=0.52$ )
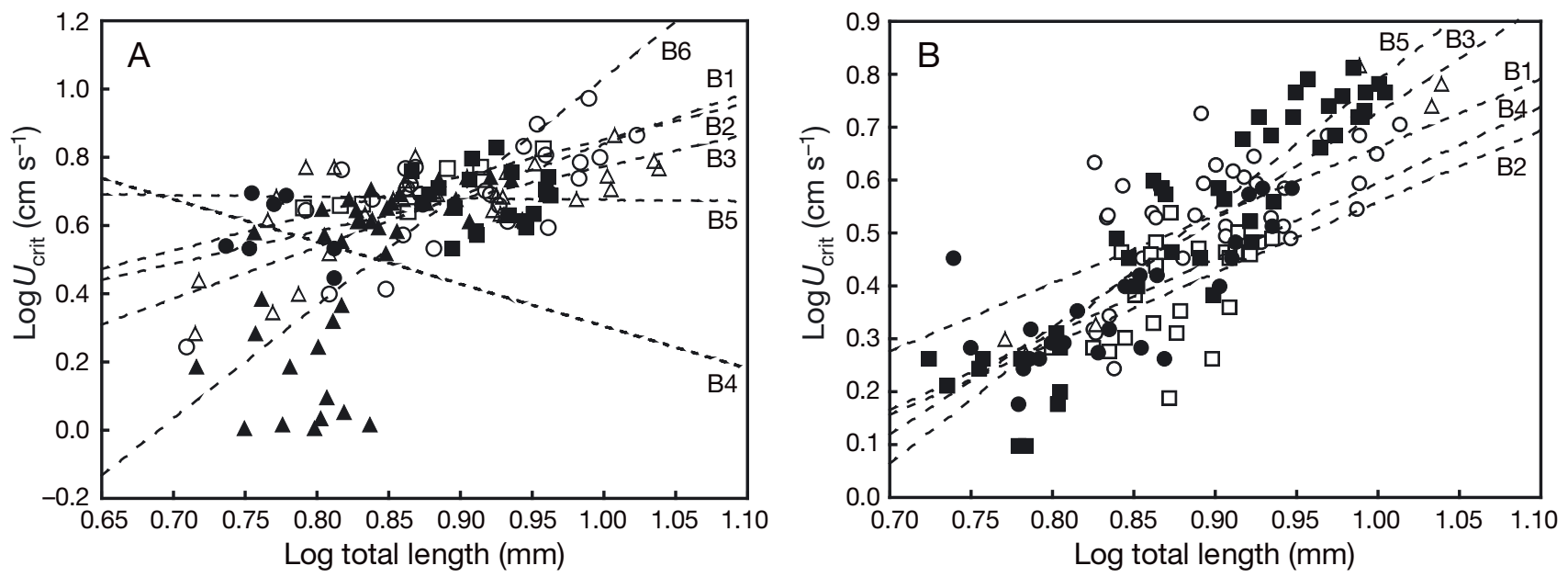

Fig. 2. (A) Lepadogaster lepadogaster and (B) L. purpurea. Ontogenetic trends for the critical swimming speeds of different batches of larvae. Each symbol represents the test result for an individual larva. Both variables are log-transformed. (- -$)$ Regression lines of each batch (B). In (A) L. lepadogaster B1 (O): $y=1.51 x-0.67$; B2 ( $\square): y=1.08 x-0.23 ; B 3(\Delta): y=0.95 x-0.18$; B4 (O):

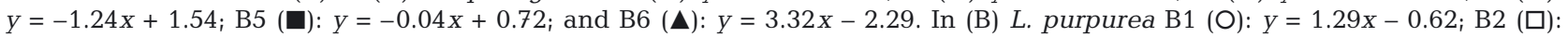
$y=1.34 x-0.78 ; \mathrm{B} 3(\Delta): y=2.03 x-1.30 ; \mathrm{B} 4(\bullet): y=1.43 x-0.84 ;$ and B5 $(\mathbf{\square}): y=2.41 x-1.63$

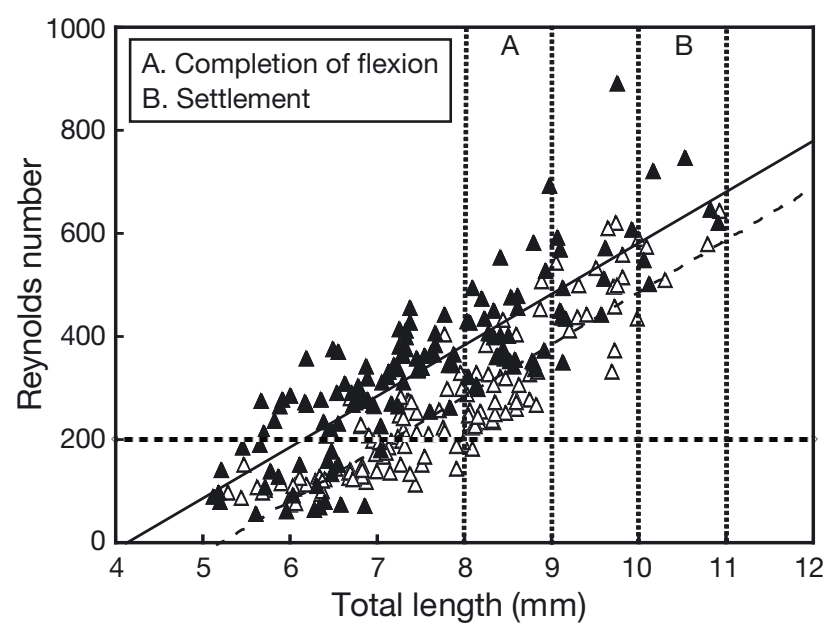

Fig. 3. Lepadogaster lepadogaster $(\mathbf{\Delta})$ and L. purpurea $(\Delta)$. Reynolds numbers $(R e)$ of larvae. (---) Transition from a viscous to an inertial environment at $R e=200$; (-) regression line for $L$. lepadogaster, (--) regression line for L. purpurea; ( $\vdots)$ size at which 2 important developmental milestones are attained: (A) completion of notochord flexion, and (B) settlement

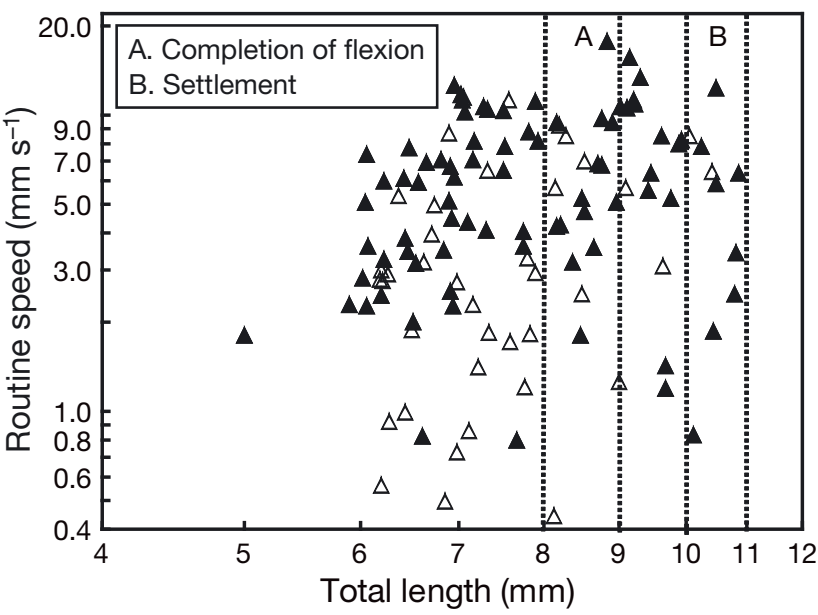

Fig. 4. Lepadogaster lepadogaster $(\mathbf{\Delta})$ and L. purpurea $(\Delta)$. Relationship between routine swimming speed and total length. Each symbol represents the mean of 4 replicates on an individual fish. Both axes are log-transformed to reflect developmental progress. (:) Size at which 2 important developmental milestones are attained: (A) completion of notochord flexion, and (B) settlement 
and no significant differences in routine swimming among cohorts in each species (L. lepadogaster: $F_{5,75}=$ $0.78, \mathrm{p}=0.57 ;$ L. purpurea: $\left.F_{4,36}=0.39, \mathrm{p}=0.81\right)$. However, ANCOVA revealed a significant effect of $\log _{10} \mathrm{TL}$ $\left(F_{1,121}=5.07, \mathrm{p}=0.03\right)$ and significant difference in routine swimming behaviour between the 2 species $\left(F_{1,121}=19.25, \mathrm{p}<0.0001\right)$.

\section{DISCUSSION}

The swimming abilities of larval fish are critical behavioural traits because swimming influences the capacity of larvae to find food, escape predators, and be dispersed (Stobutzki \& Bellwood 1994, 1997). To determine the potential importance of swimming behaviour, it is fundamental to know how abilities change during ontogeny. A few recent studies have included smaller pre-settlement larvae (e.g. Fisher et al. 2000, Clark et al. 2005, Leis et al. 2006a,b, 2007, Guan et al. 2008, Faria et al. 2009, Leis et al. 2009a,b). However, most research has focused on the swimming abilities of late-stage larvae (e.g. Stobutzki \& Bellwood 1997, Fisher \& Bellwood 2002, Fisher \& Wilson 2004, Fisher et al. 2005). Nevertheless, few incorporate the ontogeny of swimming behaviour.

The 2 gobiesocids studied here are important cryptobenthic components of the north-eastern Atlantic temperate rocky reefs (Beldade et al. 2006a). The larval stages of these fishes, particularly with respect to behavioural traits and ecology, are poorly known compared to their tropical counterparts (Leis et al. 2006a, 2009a, Faria et al. 2009). In fact, most temperate studies have focused on clupeiform, gadiform, or pleuronectiform larvae (e.g. Blaxter 1986, Miller et al. 1988), in contrast to the perciform species that are superior swimmers and comprise most tropical studies (e.g. Fisher et al. 2000, 2005, Leis \& Fisher 2006). Additionally, at all size classes, tropical perciform reef fish larvae feed and swim more efficiently using more developed sensory apparatus than other larval fishes (Leis \& McCormick 2002). Data on temperate reef fish larvae are therefore needed to address this gap.

At a given size, Lepadogaster lepadogaster swam faster than $L$. purpurea and increased swimming capacity at a greater rate. This is surprising given that these closely related species have similar morphologies, life-history trajectories, larval growth rates, size at hatching and rocky reef habitat, although $L$. purpurea shelters in larger boulders at greater depths than L. lepadogaster (Henriques et al. 2002). They differ, however, in timing of breeding ( $L$. lepadogaster spawns from March/April to June/July and L. purpurea spawns from October/November to March/April, Henriques et al. 2002). Larvae of the 2 species therefore experience different thermal environments because mean winter temperatures vary from 14.5 to $16^{\circ} \mathrm{C}$ whereas spring temperatures vary from 18 to $19.5^{\circ} \mathrm{C}$ (Henriques et al. 2002).

Temperature can affect swimming performance of fish larvae in 2 ways: by affecting muscle cells and viscosity. Fish muscle cells operate more efficiently at higher temperatures (Hunt von Herbing 2002), and temperature is linked to viscosity effects on fish larval motion (Podolsky 1994, Fuiman \& Batty 1997, Hunt von Herbing 2002). Whether larvae swim in a viscous or an inertial environment has a major effect on their swimming performance because the interaction between larvae and water in viscous environments makes swimming energetically expensive (Hunt von Herbing 2002). Recently hatched larvae of both species swim in a viscous environment $(R e<200)$. During notochord flexion, larvae improve their swimming abilities; after notochord flexion is complete, individuals swim at speeds that place them outside a strictly viscous hydrodynamic environment $(R e>200)$. Nevertheless, Lepadogaster purpurea had smaller Re than L. lepadogaster. Given that these species hatch at a similar size, and water viscosity in winter is only $5 \%$ higher than that in summer, differences in Re could be explained by the slower $U_{\text {crit }}$ of $L$. purpurea. To determine the relative importance of physical and physiological factors on swimming performance of larvae of these species, further studies are needed to quantify swimming kinematics at different temperatures, viscosities, and different sizes. In addition, there are other biological and physiological parameters that may influence swimming performance and could explain both intra- and interspecific differences in swimming performance (e.g. growth rate, Kolok \& Oris 1995; allometric growth, Muller \& Videler 1996; dietary fatty acid composition, McKenzie et al. 1998; and proportion of red muscle, Koumoundouros et al. 2009). However, these variables are beyond the scope of the present study.

In both gobiesocids, we found a roughly linear increase in $U_{\text {crit }}$ with growth over a similar size range, with an increase of 0.5 to $1.6 \mathrm{~cm} \mathrm{~s}^{-1} \mathrm{~mm}^{-1}$ growth for Lepadogaster purpurea and 0.3 to $1.2 \mathrm{~cm} \mathrm{~s}^{-1} \mathrm{~mm}^{-1}$ growth for $L$. lepadogaster. These increments are lower than speed increments reported for other pelagic, warm-temperate species $\left(1.2\right.$ to $2.6 \mathrm{~cm} \mathrm{~s}^{-1} \mathrm{~mm}^{-1}$ growth, Clark et al. 2005), which may be related to temperature and/or morphological or taxonomic differences. Guan et al. (2008) concluded from their study of ontogenetic changes in $U_{\text {crit }}$ of the shorthorn sculpin, that temperature played an important role in the development rate of $U_{\text {crit }}$ as a function of both age and size. They also hypothesized that differences in $U_{\text {crit }}$ in coldwater species are mainly related to hatching size and the degree to which water temperature influences the 
development of each species. As in other studies, critical speed varied substantially at any given size (Fisher et al. 2000, 2005, Clark et al. 2005, Leis et al. 2007, Faria et al. 2009). Although size is usually a better predictor of $U_{\text {crit }}$ than age (e.g. Clark et al. 2005, Leis et al. 2007, Faria et al. 2009), we found the reverse pattern in these clingfishes. Nevertheless, both factors were good correlates of $U_{\text {crit. }} U_{\text {crit }}$ (1 to $9.4 \mathrm{~cm} \mathrm{~s}^{-1}$ for L. lepadogaster and 1.2 to $6.5 \mathrm{~cm} \mathrm{~s}^{-1}$ for L. purpurea) were within the lower range of critical speeds reported for other temperate species (e.g. 1 to $25 \mathrm{~cm} \mathrm{~s}^{-1}$, Clark et al. 2005), and are considerably lower than critical speeds reported for tropical reef fish larvae (11.3 to $61.5 \mathrm{~cm} \mathrm{~s}^{-1}$, Leis \& Fisher 2006). Critical speeds expressed in terms of body length $\left(\mathrm{BL} \mathrm{s}^{-1}\right)$ ranged from 1.5 to $9.6 \mathrm{BL} \mathrm{s}^{-1}$ for L. lepadogaster and from 2.1 to $6.8 \mathrm{BL} \mathrm{s}^{-1}$ for L. purpurea, which are also lower than speeds reported for tropical species (10 to $20 \mathrm{BL} \mathrm{s}^{-1}$, Leis 2006).

Routine speed also increased through development, as seen in other studies (e.g. Fuiman et al. 1999, Fisher \& Bellwood 2003). However, the average routine speeds measured were low, with larvae maintaining speeds of only $\sim 18$ to $19 \%$ of their $U_{\text {crit }}(0.8$ to $17.8 \mathrm{~mm}$ $\mathrm{s}^{-1}$ for Lepadogaster lepadogaster, and 0.1 to $11.5 \mathrm{~mm}$ $\mathrm{s}^{-1}$ for $L$. purpurea). When relative swimming speeds are considered, the values reported in the present study $\left(0.02\right.$ to $\left.2 \mathrm{BL} \mathrm{s}^{-1}\right)$ are well within the range reported for other temperate species (e.g. Blaxter 1986, Miller et al. 1988, Fisher et al. 2007). However, routine swimming speeds previously reported for both tropical and subtropical species (Fuiman et al. 1999, Fisher \& Bellwood 2003) are considerably higher than those described here.

These results are consistent with the general perception that temperate species are poorer swimmers than tropical species (Stobutzki \& Bellwood 1997), but caution is needed when extrapolating between systems because there are no comparative data available for gobiesocids. Moreover, $U_{\text {crit }}$ is a laboratory measure of forced performance and it is unlikely that larvae will be able to sustain maximum critical speeds in the wild for extended periods (Leis 2006). Therefore, it is important to relate $U_{\text {crit }}$ to other swimming measurements that are more applicable in the field, such as sustained swimming speed and in situ swimming speed. Sustained swimming speed is a measure of the maximum long-term swimming abilities of larvae and their capacity to influence dispersal over extended periods of time. For instance, Fisher \& Wilson (2004) reported that settlement-stage larvae of 9 tropical species could maintain a speed of $\sim 50 \%$ of $U_{\text {crit }}$ for at least $24 \mathrm{~h}$ in the laboratory. In situ speed is measured in the field by observing larvae that are released and followed by divers, and has the advantage that larval swimming speeds are actually measured in the ocean. Leis \&
Fisher (2006) and Leis et al. (2006a) also concluded that in situ speed was $\sim 1 / 2$ of $U_{\text {crit }}$ in settlement-stage larvae of 83 species of coral-reef fishes in 11 families, and 35 to $50 \%$ over a range of developmental stages (5 to $12 \mathrm{~mm}$ standard length) in larvae of 3 warm-temperate demersal fish species. This relationship can be used to estimate swimming speeds of larvae in the ocean from laboratory measurements. Moreover, $U_{\text {crit }}$ correlates with routine swimming speed. Fisher \& Bellwood (2003) concluded that routine speed was $\sim 20 \%$ of $U_{\text {crit }}$ in 3 species (Apogonidae and Pomacentridae). Overall, $U_{\text {crit }}$ is a useful measure of maximum swimming speed that is comparable across taxa and closely correlated with other ecologically relevant measures of swimming performance such as routine speed (Fisher et al. 2005), but extrapolations require caution.

The large between species differences in routine swimming speeds might be explained not only by differences in temperature and in the swimming capacity of a given species, but also by the methodologies used. Methodological differences comprise one of the biggest difficulties in comparing routine measures of swimming speed. Factors such as tank size and volume, food distribution, starvation, light conditions, turbulence, and variability in individual behaviour, could influence the swimming speed of larvae. For example, turbulence is known to increase feeding activity (MacKenzie \& Kiorboe 1995), lower food densities increase the time spent swimming (e.g. Munk \& Kiorboe 1985), and undisturbed swimming speeds are greater at night than during the day (Fisher \& Bellwood 2003). Furthermore, external stimuli that are present in the natural environment but absent in the laboratory may mean that routine speeds measured under laboratory conditions are conservative relative to natural routine swimming speeds (Fisher \& Leis 2009). These facts collectively suggest the need to standardize methods used to measure undisturbed swimming speeds of fish larvae to maximize crossstudy comparisons.

Both critical and routine speeds increased steadily with size and age until settlement $(\sim 10 \mathrm{~mm})$; beyond this, they decreased. The lack of swimming (in the case of critical speed) or reduced swimming (in the case of routine speed) in larvae approaching settlement is probably related to behavioural changes associated with a benthic lifestyle, and not to decreased larval swimming ability. These individuals were completing metamorphosis and resembled newly settled fish, showing the presence of a ventral adhesive disk. Other studies have related changes in swimming performance to developmental or ecological transitions. In a study of sustained swimming abilities of New Zealand reef fish larvae, Dudley et al. (2000) reported that Upeneichthys lineatus (Mullidae) did not swim after 
settlement into a benthic life style. Guan et al. (2008) found that $U_{\text {crit }}$ improved steadily through ontogeny in shorthorn sculpin (Myoxocephalus scorpius) until metamorphosis, after which it slowed down. These authors also suggested that this decrease was linked to a habitat shift associated with settlement. In contrast, Fisher et al. (2000) found that coral-reef fish larval swimming ability increased slowly in early larval stages and faster in later stages, and Clark et al. (2005) found that the swimming performance of 4 species of temperate marine fishes (Sciaenidae, Sparidae, Percichthyidae) improved markedly after notochord flexion was completed. Faria et al. (2009) also reported that the critical swimming ability of red drum larvae increased more rapidly during the pelagic (pre-settlement) stage, when radical changes in body shape and structure occurred.

Whether average swimming speeds for the clingfishes reported here are sufficient to influence their location on reefs is unclear. Numerical circulation models indicate that only modest speeds (1 to $10 \mathrm{~cm} \mathrm{~s}^{-1}$ ) are required to significantly affect dispersal (e.g. Pepin \& Helbig 1997, Wolanski et al. 1997, Porch 1998). Additionally, active larval behavior can effectively reduce the dispersal of a number of taxa with varying PLD. Reef fish larvae with relatively short PLDs (e.g. pomacentrids with PLDs of 24 to 29 d) may remain near source populations (Jones et al. 1999) using simple vertical migration (Paris \& Cowen 2004). However, fishes with longer PLDs may also recruit back to source populations (Swearer et al. 1999), suggesting similar interactions with other variables. Guan et al. (2008) described an unusual swimming behaviour of the shorthorn sculpin in which larvae oriented their bodies slightly upward during critical swimming tests. This behaviour was repeatedly observed and might contribute to relevant changes in the position of larvae in the water column, although no definite conclusions were drawn. Larvae may also be able to reduce dispersal by remaining within the benthic boundary layer where flow is considerably reduced (Breitburg 1991, Breitburg et al. 1995). Postflexion or late-stage larvae of fishes spanning several temperate and tropical families have been collected in or near the benthic boundary layer (e.g. Leis 1986, Breitburg 1991, Kaufman et al. 1992, Beldade et al. 2006b). Shanks (2009) found that for many taxa with larvae that remain in the benthic boundary layer, dispersal distance is less than that predicted based on PLD. The PLD of Lepadogaster lepadogastervaries between 11 and $18 \mathrm{~d}$ (Beldade et al. 2007), which is a relatively short PLD for a temperate rocky reef species (Raventós \& Macpherson 2001). Although no information is available for L. purpurea, laboratory rearing suggests that the PLD might be slightly longer, approaching $25 \mathrm{~d}$ (A. Faria unpubl. results).
Multiple factors may similarly favour retention of gobiesocids in nearshore environments. Both study species produce demersal eggs that hatch into comparatively large, actively swimming larvae with functional eyes and developed fins and guts. Within our study area (the Arrábida Marine Park, Portugal), Beldade et al. (2006b) found that Lepadogaster spp. larvae were largely confined to the near bottom layer in all stages of development - a pattern that was confirmed in light trap studies (R. Borges et al. unpubl. results). Moreover, no larvae of these species were collected in offshore sampling (Borges et al. 2007). The advanced morphological development at hatching might facilitate active swimming to reduced-flow regions near the bottom (Breitburg 1991, Breitburg et al. 1995) and therefore reduce dispersal (Black \& Moran 1991, Black et al. 1991).

Taken together, these results indicate that clingfish larvae remain nearshore during their entire pelagic stage, most likely near the bottom, and may be particularly well adapted to these environments. Indeed, the slow speeds, near-bottom distribution of all developmental stages and short PLDs suggest that these species do not require strong swimming abilities because they do not disperse far from natal reefs. Further studies of self-recruitment and genetic differentiation in these species are needed, however, to further address these issues. Finally, caution is needed in extending inferences from laboratory reared to wild larvae because of possible differences in performance. Learned behaviours, such as avoidance, have been shown to differ between wild and reared individuals because of very different experiences (Olla et al. 1998, Brown \& Laland 2001). Therefore, measurements of larval swimming speeds in the wild are needed to infer how laboratory measurements may be extrapolated to understand ecological and life history patterns (Leis 2006). Further studies of swimming modes of fish larvae (e.g. sustained swimming) are needed to determine how they relate to $U_{\text {crit }}$ and routine speeds. Knowing when and if directed swimming takes place and under what circumstance is essential for a better understanding of how behaviour influences larval recruitment patterns and processes.

Acknowledgements. This work was supported by a PhD grant to A.F. (SFRH/BD/21742/2005), and through the Pluriannual Program (R \& D Unit 331/94), financed by Fundação para a Ciência e a Tecnologia.

\section{LITERATURE CITED}

Beldade R, Erzini K, Gonçalves EJ (2006a) Composition and temporal dynamics of a temperate rocky cryptobenthic fish assemblage. J Mar Biol Assoc UK 86:1221-1228 
Beldade R, Borges R, Gonçalves EJ (2006b) Depth distribution of nearshore temperate fish larval assemblages near rocky substrates. J Plankton Res 28:1003-1013

Beldade R, Pedro T, Gonçalves EJ (2007) Pelagic larval duration of 10 temperate cryptobenthic fishes. J Fish Biol 71: $376-382$

Black KP, Moran PJ (1991) Influence of hydrodynamics on the passive dispersal and initial recruitment of larvae of Acanthaster planci (Echinodermata: Asteroidea) on the Great Barrier Reef. Mar Ecol Prog Ser 69:55-65

Black KP, Moran PJ, Hammond LS (1991) Numerical models show coral reefs can be self-seeding. Mar Ecol Prog Ser $74: 1-11$

> Blaxter JHS (1986) Development of sense organs and behaviour of teleost larvae with special reference to feeding and predator avoidance. Trans Am Fish Soc 115:98-114

Borges R, Ben-Hamadou R, Chícharo MA, Ré P, Gonçalves EJ (2007) Horizontal spatial and temporal distribution patterns of nearshore larval fish assemblages at a temperate rocky shore. Estuar Coast Shelf Sci 71:412-428

Bradbury IR, Laurel B, Snelgrove PVR, Bentzen P, Campana SE (2008) Global patterns in marine dispersal estimates: the influence of geography, taxonomic category and life history. Proc Biol Sci 275:1803-1810

Breitburg DL (1991) Settlement patterns and presettlement behavior of the naked goby, Gobiosoma bosci, a temperate oyster reef fish. Mar Biol 109:213-221

Breitburg DL, Palmer MA, Loher T (1995) Larval distributions and the spatial patterns of settlement of an oyster reef fish: responses to flow and structure. Mar Ecol Prog Ser 125: $45-60$

Brett JR (1964) The respiratory metabolism and swimming performance of young sockeye salmon. J Fish Res Board Can 21:1183-1226

Briggs JC (1955) A monograph of the clingfishes (Order Xenopterygii). Stanford Ichthyol Bull 6:1-224

Briggs JC (1986) Gobiesocidae. In: Whitehead PJP, Bauchot M-L, Hureau J-C, Nielsen J, Tortonese E (eds) Fishes of the North-eastern Atlantic and the Mediterranean, Vol 3. UNESCO, Paris, p 1351-1359

> Brogan MW (1994) Distribution and retention of larval fishes near reefs in the Gulf of California. Mar Ecol Prog Ser 115: $1-13$

Brown C, Laland K (2001) Social learning and life skills training for hatchery reared fish. J Fish Biol 59:471-493

> Clark DL, Leis JM, Hay AC, Trnski T (2005) Swimming ontogeny of larvae of four temperate marine fishes. Mar Ecol Prog Ser 292:287-300

Cowen RK, Paris CB, Olson DB, Fortuna JL (2002) The role of long distance dispersal versus local retention in replenishing marine populations. Gulf Caribb Res 14:129-137

> Depczynski M, Bellwood DR (2003) The role of cryptobenthic reef fishes in coral reef trophodynamics. Mar Ecol Prog Ser 256:183-191

> Dudley B, Tolimieri N, Montgomery J (2000) Swimming ability of the larvae of some reef fishes from New Zealand waters. Mar Freshw Res 51:783-787

Faria A, Ojanguren A, Fuiman L, Gonçalves E (2009) Ontogeny of critical swimming speed of wild-caught and laboratory-reared larvae of red drum Sciaenops ocellatus larvae. Mar Ecol Prog Ser 384:221-230

> Fisher R (2005) Swimming speeds of larval coral reef fishes: impacts on self-recruitment and dispersal. Mar Ecol Prog Ser 285:223-232

Fisher R, Bellwood DR (2002) A light trap design for stratumspecific sampling of reef fish larvae. J Exp Mar Biol Ecol 269:27-37
Fisher R, Bellwood DR (2003) Undisturbed swimming behaviour and nocturnal activity of coral reef fish larvae. Mar Ecol Prog Ser 263:177-188

Fisher R, Leis JM (2009) Swimming speeds in larval fishes: from escaping predators to the potential for long distance migration. In: Domenici P, Kapoor BG (eds) Fish locomotion: an eco-ethological perspective. Science Publishers, Enfield, NH, p 333-373

Fisher R, Wilson SK (2004) Maximum sustainable swimming speeds of late-stage larvae of nine species of reef fishes. J Exp Mar Biol Ecol 312:171-186

Fisher R, Bellwood DR, Job SD (2000) Development of swimming abilities in reef fish larvae. Mar Ecol Prog Ser 202: 163-173

Fisher R, Leis JM, Clark DL, Wilson SK (2005) Critical swimming speeds of late-stage coral reef fish larvae: variation within species, among species and between locations. Mar Biol 147:1201-1212

Fisher R, Sogard SM, Berkeley SA (2007) Trade-offs between size and energy reserves reflect alternative strategies for optimizing larval survival potential in rockfish. Mar Ecol Prog Ser 344:257-270

Fuiman LA (2002) Special considerations of fish eggs and larvae. In: Fuiman LA, Werner RG (eds) Fishery sciencethe unique contributions of early life stages. Blackwell Science, Oxford, p $1-32$

- Fuiman LA, Batty RS (1997) What a drag it is getting cold: partitioning the physical and physiological effects of temperature on fish swimming. J Exp Biol 200:1745-1755

Fuiman LA, Ottey DR (1993) Temperature effects on spontaneous behavior of larval and juvenile red drum Sciaenops ocellatus, and implications for foraging. Fish Bull 91:23-35

Fuiman LA, Smith ME, Malley VN (1999) Ontogeny of routine swimming speed and startle responses in red drum, with a comparison of responses to acoustic and visual stimuli. J Fish Biol 55:215-226

Gonçalves DM, Gonçalves EJ, Almada VC, Almeida SP (1998) Comparative behaviour of two species of Lepadogaster (Pisces: Gobiesocidae) living at different depths. J Fish Biol 53:447-450

Guan L, Snelgrove PVR, Gamperl AK (2008) Ontogenetic changes in the critical swimming speed of Gadus morhua (Atlantic cod) and Myoxocephalus scorpius (shorthorn sculpin) larvae and the role of temperature. J Exp Mar Biol Ecol 360:31-38

> Henriques M, Lourenço R, Almada F, Calado G and others (2002) A revision of the status of Lepadogaster lepadogaster (Teleostei: Gobiesocidae): sympatric subspecies or a long misunderstood blend of species? Biol J Linn Soc 76: $327-338$

Hickford MJ, Schiel DR (2003) Comparative dispersal of larvae from demersal versus pelagic spawning fishes. Mar Ecol Prog Ser 252:255-271

> Hunt von Herbing I (2002) Effects of temperature on larval fish swimming performance: the importance of physics to physiology. J Fish Biol 61:865-876

> Jones GP, Milicich MJ, Emslie MJ, Lunow C (1999) Selfrecruitment in a coral reef fish population. Nature 402 : 802-804

Kaufman L, Ebersole J, Beets J, McIvor CC (1992) A key phase in the recruitment dynamics of coral reef fishes: post-settlement transition. Environ Biol Fishes 34:109-118

Kingsford MJ, Choat JH (1989) Horizontal distribution patterns of presettlement reef fish: Are they influenced by the proximity of reefs? Mar Biol 101:285-287

Kolok AS, Oris JT (1995) The relationship between specific growth rate and swimming performance in male fathead 
minnows (Pimephales promelas). Can J Zool 73: 2165-2167

Koumoundouros G, Ashton C, Xenikoudakis G, Giopanou I, Georgakopoulou E, Stickland N (2009) Ontogenetic differentiation of swimming performance in gilthead seabream (Sparus aurata, Linnaeus 1758) during metamorphosis. J Exp Mar Biol Ecol 370:75-81

La Mesa GM, Micalizzi M, Giaccone G, Vacchi M (2004) Cryptobenthic fishes of the "Ciclopi Islands" marine reserve (central Mediterranean Sea): assemblage composition, structure and relations with habitat features. Mar Biol 145:233-242

Leis JM (1986) Epibenthic schooling by larvae of the clupeid fish Spratelloides gracilis. Jap J Ichthyol 33:67-69

Leis JM (2006) Are larvae of demersal fishes plankton or nekton? Adv Mar Biol 51:57-141

> Leis JM, Carson-Ewart BM (1997) In situ swimming speeds of the late pelagic larvae of some Indo-Pacific coral-reef fishes. Mar Ecol Prog Ser 159:165-174

Leis JM, Fisher R (2006) Swimming speed of settlement-stage reef-fish larvae measured in the laboratory and in the field: a comparison of critical speed and in situ speed. Proc 10th Int Coral Reef Symp, Okinawa, 438-445

> Leis JM, Goldman B (1987) Composition and distribution of larval fish assemblages in the Great Barrier Reef Lagoon, near Lizard Island, Australia. Aust J Mar Freshw Res 38:211-223

Leis JM, McCormick MI (2002) The biology, behavior, and ecology of the pelagic, larval stage of coral reef fishes. In: Sale PF (ed) Coral reef fishes: dynamics and diversity in a complex ecosystem. Academic Press, San Diego, CA, p171 -200

Leis JM, Miller JM (1976) Offshore distributional patterns of Hawaiian fish larvae. Mar Biol 36:359-367

Leis JM, Stobutzki IC (1999) Swimming performance of late pelagic larvae of coral-reef fishes: in situ and laboratorybased measurements. In: Séret B, Sire JY (eds) Proc 5th Indo-Pacific Fish Conf, Nouméa, 1997. Société Française d'Ichtyologie et Institut de Recherche pour le Développement, Paris, p 575-583

Leis JM, Hay AC, Trnski T (2006a) In situ ontogeny of behaviour in pelagic larvae of three temperate, marine, demersal fishes. Mar Biol 148:655-669

Leis JM, Hay AC, Clark DA, Chen IS, Shao KT (2006b) Behavioral ontogeny in larvae and early juveniles of the giant trevally, Caranx ignobilis (Pisces: Carangidae). Fish Bull 104:401-414

Leis JM, Hay AC, Lockett MM, Chen JP, Fang LS (2007) Ontogeny of swimming speed in larvae of pelagic-spawning, tropical, marine fishes. Mar Ecol Prog Ser 349: 255-267

Leis JM, Hay AC, Howarth GJ (2009a) Ontogeny of in situ behaviours relevant to dispersal and population connectivity in larvae of coral-reef fishes. Mar Ecol Prog Ser 379: 163-179

Leis JM, Piola RF, Hay AC, Wen C, Kan KP (2009b) Ontogeny of behaviour relevant to dispersal and connectivity in the larvae of two non-reef demersal, tropical fish species. Mar Freshw Res 60:211-223

Lester SE, Ruttenberg BI (2005) The relationship between pelagic larval duration and range size in tropical reef fishes: a synthetic analysis. Proc Biol Sci 272:585-591

MacKenzie BR, Kiorboe T (1995) Encounter rates and swimming behavior of pause-travel and cruise larval fish predators in calm and turbulent laboratory environments. Limnol Oceanogr 40:1278-1289

Marliave JB (1986) Lack of planktonic dispersal of rocky intertidal fish larvae. Trans Am Fish Soc 115:149-154

McKenzie DJ, Higgs DA, Dosanjh BS, Deacon G, Randall DJ
(1998) Dietary fatty acid composition influences swimming performance in Atlantic salmon (Salmo salar) in seawater. Fish Physiol Biochem 19:111-122

Miller PJ (1979) Adaptiveness and implications of small size in teleosts. Symp Zool Soc Lond 44:263-306

- Miller TJ, Crowder LB, Rice JA, Marschall EA (1988) Larval size and recruitment mechanisms in fishes: toward a conceptual framework. Can J Fish Aquat Sci 45:1657-1688

> Muller UK, Videler JJ (1996) Inertia as a 'safe harbour': Do fish larvae increase length growth to escape viscous drag? Rev Fish Biol Fish 6:353-360

- Munk P, Kiorboe T (1985) Feeding behavior and swimming activity of larval herring (Clupea harengus) in relation to density of copepod nauplii. Mar Ecol Prog Ser 24:15-21

Olla BL, Davis MW, Ryer CH (1998) Understanding how the hatchery environment represses or promotes the development of behavioral survival skills. Bull Mar Sci 62: $531-550$

Paris CB, Cowen RK (2004) Direct evidence of a biophysical retention mechanism for coral reef fish larvae. Limnol Oceanogr 49:1964-1979

> Pepin P, Helbig JA (1997) Distribution and drift of Atlantic cod (Gadus morhua) eggs and larvae on the northeast Newfoundland Shelf. Can J Fish Aquat Sci 54:670-685

> Plaut I (2001) Critical swimming speed: its ecological relevance. Comp Biochem Physiol Comp Physiol 131:41-50

Podolsky RD (1994) Temperature and water viscosity: physiological versus mechanical effects on suspension feeding. Science 265:100-103

- Porch CE (1998) A numerical study of larval fish retention along the southeast Florida coast. Ecol Model 109:35-59

> Raventós N, Macpherson E (2001) Planktonic larval duration and settlement marks on the otoliths of Mediterranean littoral fishes. Mar Biol 138:1115-1120

Sabatés A, Zabala M, Gárcia-Rubies A (2003) Larval fish communities in the Medes Islands Marine Reserve (Northwest Mediterranean). J Plankton Res 25:1035-1046

> Shanks AL (2009) Pelagic larval duration and dispersal distance revisited. Biol Bull 216:373-385

Snelgrove PVR, Bradbury IR, deYoung B, Fraser S (2008) Temporal variation in fish egg and larval production by pelagic and bottom spawners in a large Newfoundland coastal embayment. Can J Fish Aquat Sci 65:159-175

Sponaugle SC, Robert K, Shanks A, Morgan SG and others (2002) Predicting self-recruitment in marine populations: biophysical correlates and mechanisms. Bull Mar Sci 70: 341-375

> Stobutzki IC (1998) Interspecific variation in sustained swimming ability of late pelagic stage reef fish from two families (Pomacentridae and Chaetodontidae). Coral Reefs 17: 111-119

Stobutzki IC, Bellwood DR (1994) An analysis of the sustained swimming abilities of pre- and post-settlement coral reef fishes. J Exp Mar Biol Ecol 175:275-286

Stobutzki IC, Bellwood DR (1997) Sustained swimming abilities of the late pelagic stages of coral reef fishes. Mar Ecol Prog Ser 149:35-41

Suthers IM, Frank KT (1991) Comparative persistence of marine fish larvae from pelagic versus demersal eggs off southwestern Nova Scotia, Canada. Mar Biol 108:175-184

Swearer SE, Caselle JE, Lea DW, Warner RR (1999) Larval retention and recruitment in an island population of a coral-reef fish. Nature 402:799-802

Swearer SE, Shima JS, Hellberg ME, Thorrold SR and others (2002) Evidence of self-recruiment in demersal marine populations. Bull Mar Sci 70:251-271

Taylor MS, Hellberg ME (2003) Genetic evidence for local 
retention of pelagic larvae in a Caribbean reef fish. Science 299:107-109

Thresher RE (1984) Reproduction in reef fishes. TFH Publications, Neptune City, NJ, p 399

Thresher RE, Colin PL, Bell LJ (1989) Planktonic duration, distribution and population structure of western and central Pacific damselfishes (Pomacentridae). Copeia 1989: 420-434

Tilney RL, Nelson G, Radloff SE, Buxton CD (1996) Ichthy-

Editorial responsibility: Paul Snelgrove,

St. John's, Newfoundland and Labrador, Canada oplankton distribution and dispersal in the Tsitsikamma National Park Marine Reserve, South Africa. S Afr J Mar Sci 17:1-14

> Webb PW, Weihs D (1986) Functional locomotor morphology of early life history stages of fishes. Trans Am Fish Soc 115: 115-127

Wolanski E, Dohery PJ, Carelton J (1997) Directional swimming of fish larvae determines connectivity of fish populations on the Great Barrier Reef. Naturwissenschaften 84:262-268

Submitted: November 30, 2009; Accepted: June 3, 2010

Proofs received from author(s): August 22, 2010 